La consagración

de la primavera $y$

el nacimiento de la música

contemporánea europea

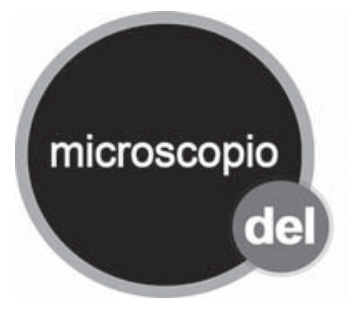

del

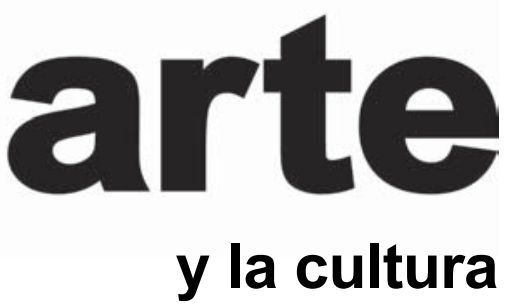

En el París de comienzos del siglo XX destacaban los ballets rusos del empresario Sergei Diagilev, quien había encargado piezas para la escena a los más importantes músicos de la época. Colaboraron con él

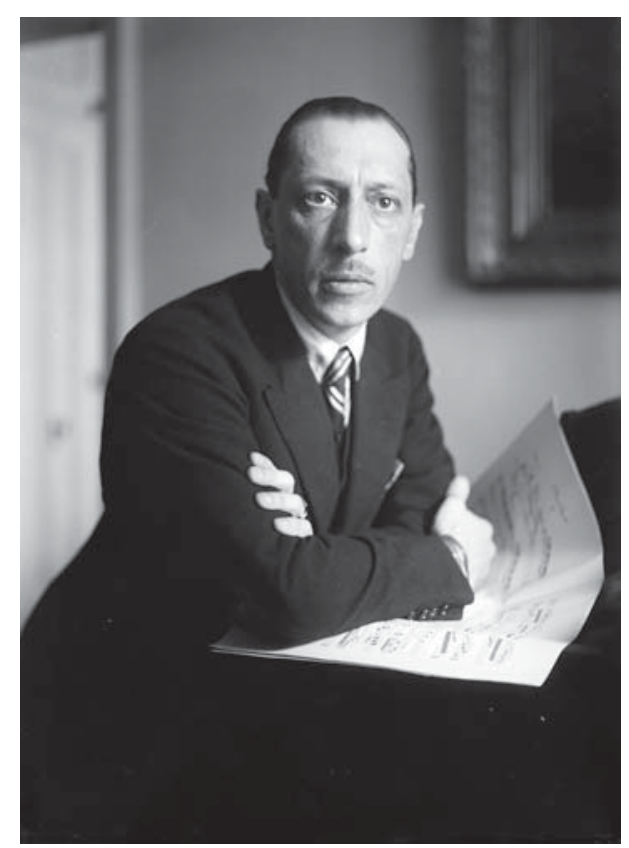

Igor Stravinsky (1882-1971). Wikimedia Commons.
Claude Debussy, Maurice Ravel, Erik Satie, Richard Strauss y Manuel de Falla, así como los pintores Pablo Picasso y Georges Braque. $\mathrm{Su}$ estilo se inscribía en el movimiento de vanguardia y explotaba cierto sabor exótico, con coreografías alejadas de los cánones del ballet clásico.

En 1909, un joven compositor ruso, llamado Igor Stravinsky, recibió de Diagilev el encargo de componer un ballet. Es así como nacen El pájaro de fuego y posteriormente Petruchka. Paulatinamente Stravinsky va derivando de los temas rusos a lo que sería la más fenomenal y violenta ruptura con los cánones musicales de la época, donde claves diferentes se encuentran extrañamente yuxtapuestas y superpuestas unas sobre otras, para lograr un acre efecto politonal.

Todo estaba preparado para lo inevitable: la noche del 29 de mayo de 1913 sube al podio del Teatro de los Campos Elíseos de París el director Pierre Monteaux para dirigir el estreno del ballet La consagración de la primavera, por los bailarines rusos con música de Stravinsky y coreografía de Nizhinski. Esta obra puede considerarse como una pieza inicial de la música clásica del siglo XX. A partir de ella, el estilo rupturista domina el panorama musical europeo en todas sus di- mensiones, como la melodía, la forma y el timbre y su estreno suscitó el mayor escándalo de la historia, en la ejecución de una obra musical.

El argumento trata del sacrificio ritual de una joven virgen, bailando hasta la muerte ante su tribu, para celebrar la llegada de la primavera, en la Rusia arcaica, pagana y primitiva. La atrevida coreografía de Nizhinski, el vestuario ligero de los bailarines y los decorados modernistas de Roerich resultaron demasiado provocativos para la conservadora sociedad parisina. A medida que se desarrollaba, la música constituía una tremenda sacudida para los oyentes.

Stravinsky utiliza unos medios de expresión extraños y mucho más violentos que los acostumbrados en las salas de París. La melodía apenas existe y se mueve en tonalidades extrañas: escalas orientales, modalidades litúrgicas y acentuados cromatismos; las armonías son audaces y provocadoras; el carácter principal es rítmico, un ritmo bárbaro, fantástico y estimulante.

Posteriormente, Stravinsky abandonaría la vanguardia y optaría por formas neoclásicas, al tiempo que negros nubarrones se cernían sobre Europa preludiando el comienzo de la primera guerra mundial.

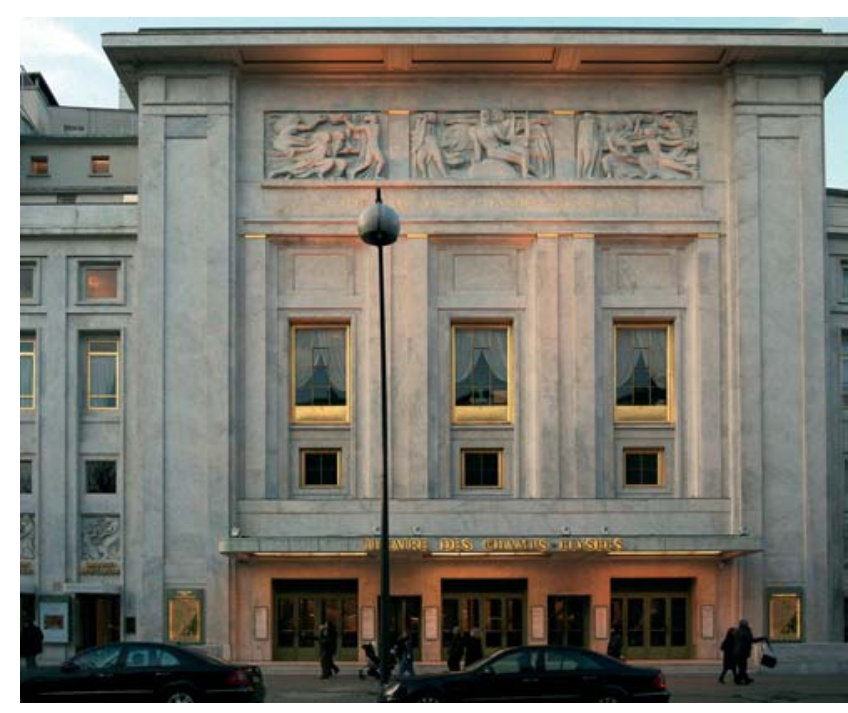

Teatro de los Campos Elíseos, París. Wikimedia Commons.

\section{El escándalo}

Desde el primer compás empezaron a oírse en el público expresiones de desaprobación. Las protestas aumentaron cuando se levantó el telón y apareció el decorado del pintor Nicolás Roerich. Más tarde, la orquesta fue ahogada por un furibundo griterío de protestas. Los compositores Camille Saint Saëns y Theodor Dubois expresaron su repulsa en voz bien alta y clara, llamando farsante a Stravinsky, mientras que Maurice Ravel, amigo del compositor, gritaba que era una obra genial; Claude Debussy pedía silencio para que pudiera oírse aquella música maravillosa, y Florent Schmidt llamaba cretino al embajador austríaco.

Fue una batalla campal en la que participaron incluso las damas, llegando a concertarse varios duelos que al día siguiente se llevaron a efecto.

\section{Referencias}

1.- Untermeyer L. Igor Stravinsky en Forjadores del mundo moderno: Editorial Grijalbo, 1960, México D.F.

2.- Salaberri S. Igor Stravinsky. La consagración de la primavera. http://www.tolosa 750.net/es/IgorStravinsky.pdf. (Accedido el 4 de marzo de 2009).

Texto: Ernesto Payá G. 